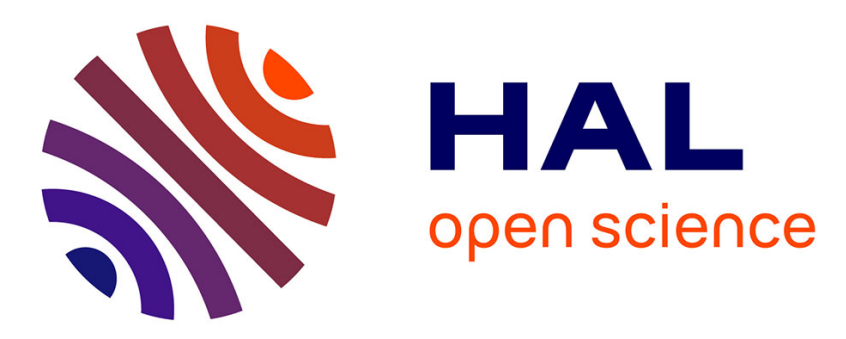

\title{
Numerical modeling of laser-induced shock experiments for the development of the adhesion test for bonded composite materials
}

Romain Ecault, Fabienne Touchard, Michel Boustié, Laurent Berthe, Nicolas Dominguez

\section{To cite this version:}

Romain Ecault, Fabienne Touchard, Michel Boustié, Laurent Berthe, Nicolas Dominguez. Numerical modeling of laser-induced shock experiments for the development of the adhesion test for bonded composite materials. Composite Structures, 2016, 152, pp.382-394. 10.1016/j.compstruct.2016.05.032 . hal-02290960

\section{HAL Id: hal-02290960 https://hal.science/hal-02290960}

Submitted on 18 Sep 2019

HAL is a multi-disciplinary open access archive for the deposit and dissemination of scientific research documents, whether they are published or not. The documents may come from teaching and research institutions in France or abroad, or from public or private research centers.
L'archive ouverte pluridisciplinaire HAL, est destinée au dépôt et à la diffusion de documents scientifiques de niveau recherche, publiés ou non, émanant des établissements d'enseignement et de recherche français ou étrangers, des laboratoires publics ou privés. 


\title{
Numerical modeling of laser-induced shock experiments for the development of the adhesion test for bonded composite materials
}

\author{
Romain Ecault $^{\mathrm{a}, *}$, Fabienne Touchard ${ }^{\mathrm{b}}$, Michel Boustie ${ }^{\mathrm{b}}$, Laurent Berthe $^{\mathrm{c}}$, Nicolas Dominguez ${ }^{\mathrm{a}}$ \\ ${ }^{a}$ Airbus Group Innovations, Campus Engineering (D42/D41), BP90112, 31703 Blagnac, France

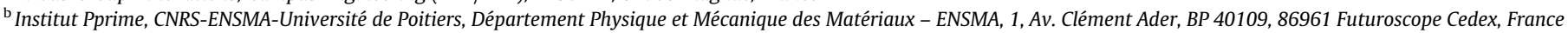 \\ ' PIMM, CNRS-ENSAM Paristech, 151 Bd de l'Hôpital, 75013 Paris Cedex, France
}

Keywords:

Shock propagation modeling

CFRP composites

Laser-induced shock

Bonded composites

Adhesion test

Bonding quality assessment

\begin{abstract}
A B S T R A C T
In this work, laser shock experiments on composite material are modeled. Focus is made on the development of a reliable numerical model to be used for the laser shock wave adhesion test of bonded composites. Technique principle is explained as well as the laser shock experiment procedure. Then, the numerical investigations are presented. A calibration method is given to set the model input parameters, and the modeling choices are detailed. Dynamic material parameters are identified thanks to experimental results, and validated through a complete campaign of laser shocks on various carbon fiber reinforced plastic (CFRP) materials (monolithic and bonded). Finally, numerical results for bonded composites are discussed. They enable to understand the stress distribution within the composite assembly during the wave propagation. This is a key step toward the development of a reliable and controlled laser shock adhesion test.
\end{abstract}

\section{Introduction}

Composite bonding is an important step toward the development of lighter aeronautic structures. It enables to significantly reduce the global mass, by replacing the conventional assembly techniques for which rivets and fasteners have to be used. It can also lead to faster production, since large panels can be bonded in once. These two main advantages can clearly increase the aircrafts eco-efficiency, during their production and during their life time. Efficient bonding can also enable the use of new assembly configurations. However, the quality of bonding must be ensured and variability in the resulting mechanical performances avoided. It requires a good knowledge of the materials - especially of their adherent surfaces - and a good mastering of operation conditions so that the full process is under control. Finally the quality of bonding should be quantified. A non-destructive evaluation of bonding, giving access to a quantitative evaluation of the bonding quality, is so far not possible with the existing technologies. Consequently, many researches currently address the evaluation of bonding quality, and they are more specifically dedicated to the weak bond issue. A weak bond is a mechanical weakness of the joint. While debonding can easily be detected by ultrasound testing, weak

\footnotetext{
* Corresponding author.

E-mail address: romain.ecault@airbus.com (R. Ecault).
}

bonding cannot since no air gap is present between the two bonded surfaces - there is cohesion, but poor. Weak bond strength should be equal or less to $20 \%$ of the bond nominal strength, and its failure should be adhesive. Such bonds can result from poor curing or from a specific contamination prior to bonding process for example. An extremely weak bond is called "kissing bond" in the literature, which defines a perfect bond geometrically speaking, but with no adherence.

These years, several techniques are developed for this purpose. ENCOMB European project (Extended Non-Destructive Testing of Composite Bonds) is a good example of the research efforts dedicated to NDT of bonding. For elements of context, see [1-3]. Selected ENCOMB results are given in [1-19]. The first step is to control adherent surfaces by inspecting the parts before bonding process. Techniques dedicated to this control are not described in details in this paper, but references are given [4-8]. The next step is to detect the presence of a contaminant once the part bonded and/or to reveal the consequence of this contamination, namely weak bonding. Detect an inner contaminant is not an easy task since there is no direct access to the surface anymore. Different under-development techniques address this issue. For examples, guided waves, monitored by a laser-scanning vibrometer, have shown good sensitivity to water contamination [9]. Electromechanical impedance measurements have shown the technique potential to reveal the presence of release agent or moisture, as 
well as poor curing $[10,11]$. Good detection potential has been demonstrated with active thermography for some applications [12]. The possibility of using optical fiber-grating sensors directly placed in the bondline has been studied [13-15]. Conventional [16], laser [17,18] and non-linear [19] ultrasound testing methods have also been investigated. Nevertheless, none of these techniques enables a mechanical quantification of the tested bond and thus cannot address the weak bond issue. From this point of view, the laser shock adhesion test (LASAT), discussed in this paper, is different. Using laser-induced shock waves, it enables to load the bond with a given level of stresses, thus giving a quantification of its strength. The technique capability has already been shown for various applications, mainly thanks to experimental works [20-24]. Especially, the technique enables to discriminate different levels of contaminations $[25,26]$. Progress is pending on reliable numerical modeling. Indeed, it enables to evaluate the generated stresses in the target. This is challenging because few works addressed the modeling of laser shock experiments, and even less study the modeling of laser shock on composite material.

In the literature, several investigations address to damage modeling of composite materials under quasi static loading. In particular, efforts are made to correctly model delamination initiation and propagation in carbon fiber reinforced polymer materials (CFRP). For example, cohesive laws are developed and validated by comparison to GIC or GIIC experiments [27,28]. Sensitivity to low strain rate dynamic loading has also been investigated. Next step is to validate these laws in case of low velocity impact such as dropweight or drop tower. Investigations were also performed in case of preloaded CFRP plate to improve the damage tolerance of structures [29]. LS-DYNA software composite models and tiebreak contact laws were used and showed good results in comparison with experimental results [30,31]. In these models, the Chang/Chang criterion is used as damage initiation criterion [32]. Even in these classical cases, the relevance of the used model parameters and their validation are quite important as shown by some studies $[33,34]$. Two other works can be quoted from Faggiani et al. and Lopes et al. [35,36]. They both present the development of an intralaminar damage model based on different approaches. Developments were included in ABAQUS software. When shell elements can be used in case of low energy impacts, solid elements are usually implemented for high energy impacts [37-46]. It enables to correctly describe the shock wave propagation through the composite thickness. In these impact cases, damage prediction and evaluation of mechanical performances are aimed. Applications cover hailstone impacts, military armour, crashworthiness, or space structures $[37,38]$. Other works focus on the development and validation of a more complex damage propagation model to obtain a more realistic damage representation [39-42]. This is the case of the model implemented in RADIOSS and based on the LMT model (Laboratoire de Mecanique et Technologie, ENS Cachan) [40]. Another model, including a progressive softening of material properties is taken into account by a LS-DYNA model (developed by Materials Sciences Corporation) [41]. The damage model efficiency has been demonstrated on two ballistic experiments, for which the damage extent were correctly described [41]. It has also been used to model ballistic impact on balsa composite and GFRP [42]. These models enable a better damage description, but the wave propagation description is another task. Several works thus address to the development of material models including equation of state dedicated to composite materials [43-46]. In these studies, the question of strain rate effects on the material mechanical properties is also raised $[45,46]$. But, to our knowledge and except in [23], almost no work has been published concerning the modeling of laser shock on composite material, taking into account the wave propagation and the damage creation.
In this paper, numerical modeling of laser shock test on composite materials is performed and compared with experimental results. Laser shock principle is first described to highlight the key points of the technique. The experimental setup and procedure are then detailed to explain how experimental results were obtained. After a description of the numerical models and preliminary studies, the numerical results are given. It includes results for thin and thick unidirectional composites, and for an example of bonded composites. Focus is made on the parameter identification, and on the model validations. Finally, the interest of the reliable numerical model developed in this paper for the LASAT simulation is discussed.

\section{Laser shock experiments}

\subsection{Laser shock principle}

Laser shock technique is based on laser/matter interaction and shock theory. To generate a laser-induced shock wave inside a material, a high power laser is focused on its surface. Because of the high level of energy, the laser/matter interaction results in a plasma expansion, generating by reaction a shock wave in the material. The pressure level resulting from the irradiation depends on material characteristics and on the presence or not of a confinement medium (see in Fig. 1a). Typically, interaction is now wellknown for aluminum. In this case, effect of confinement has been studied $[47,48]$. In this work, laser shocks are produced on composite target. An aluminum painting is used as a sacrificial layer. Laser/matter interaction is forced with the aluminum for the given reasons. Water confinement is used, and focus spot is $4 \mathrm{~mm}$ diameter. The shock wave then propagates inside the material, according to characteristics which depend on the material, especially its density and sound speed. The pressure level is fixed by the shock Hugoniot of the shocked material (see Fig. 1b and c). When reaching the sample back face, the shock front is reflected into a release wave due to the presence of a free surface. This wave brings back the pressure to zero, but accelerates the particle velocity. This matter state finally crosses the release state associated with the main unloading wave coming from the front face. Resulting state is inside tensile loading (see state (4) in Fig. 1c). Considering 1Dhypothesis, a homogeneous material target and no attenuation, the tensile level is the opposite of the induced pressure level. Then, two cases can be considered. If the failure stress $\sigma_{r 1}$ is lower than the induced tensile stresses, then damage occurs [49-51]. If the failure stress $\sigma_{r 2}$ is higher than the tensile level, then the material remains unharmed after the wave propagation. These two cases have two different features on the back face velocity. Therefore, they can be identified by monitoring the free surface velocity, with a VISAR probe for example (see in Figs. 1a and 2 for deeper explanations).

\subsection{Back face velocity measurements}

In this work, T800/M21 composite laminates are used to gather experimental data. All the samples come from the same bulk material. This plate is a unidirectional T800/M21 material, measuring $3 \mathrm{~mm}$ thick, and made of 12 plies of $250 \mu \mathrm{m}$ each. It contains carbon fibers into thermoset resin, loaded with elastomer nodules. Amount of fiber is $66 \%$. From this plate, samples were cut for laser shock experiment. Their approximate size is 10 per $10 \mathrm{~mm}$. Then, some samples were hand-polished to get various thicknesses:

- $0.5 \mathrm{~mm}$ samples, made of two layers, were dedicated to shock experiments with back face velocity measurements. Results are used in Fig. 2 as illustration, then in Figs. 6 and 7 for comparing to numerical results. 

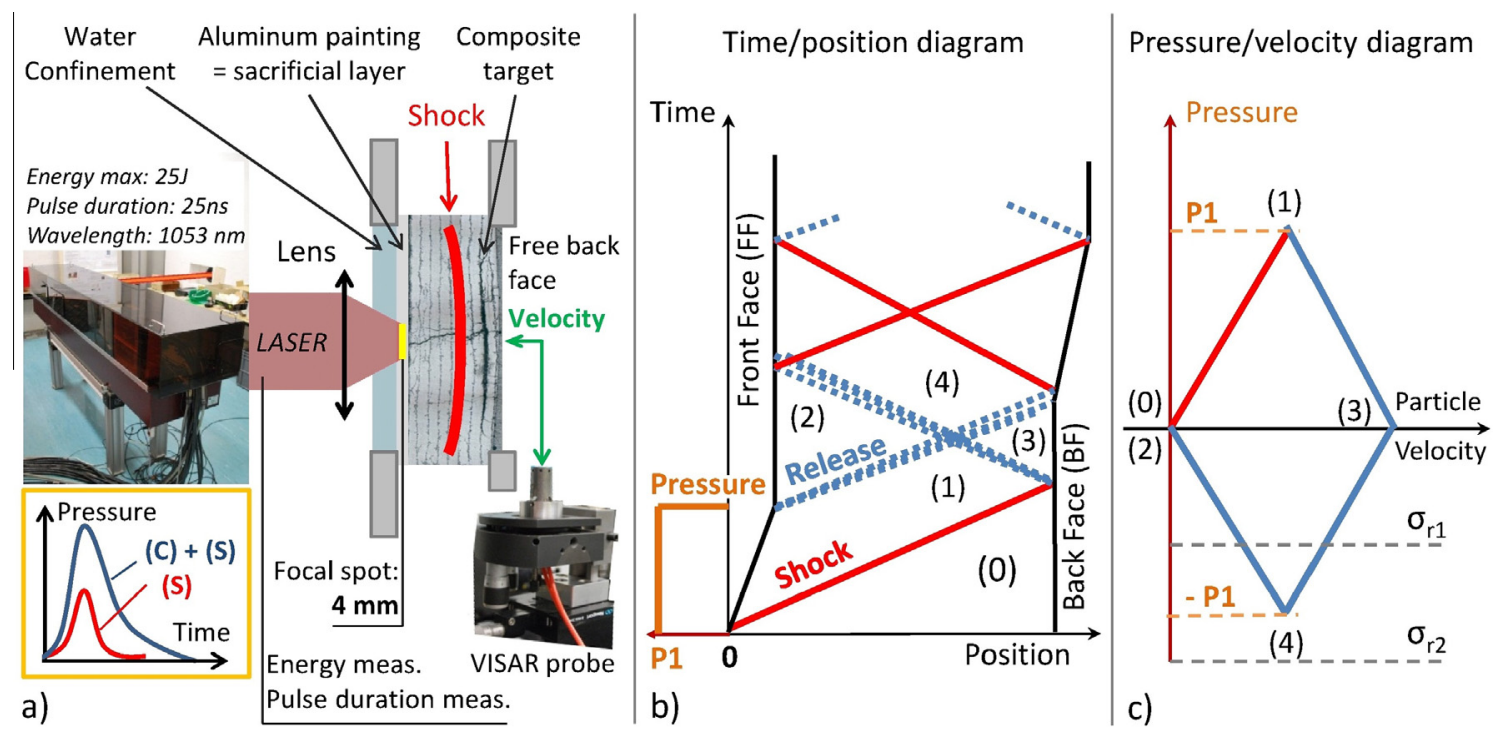

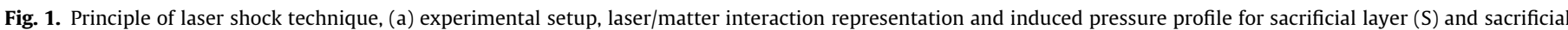

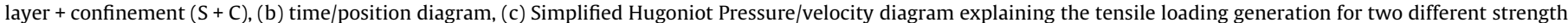
values $\left(\sigma_{r 1}\right.$ and $\left.\sigma_{r 2}\right)$.

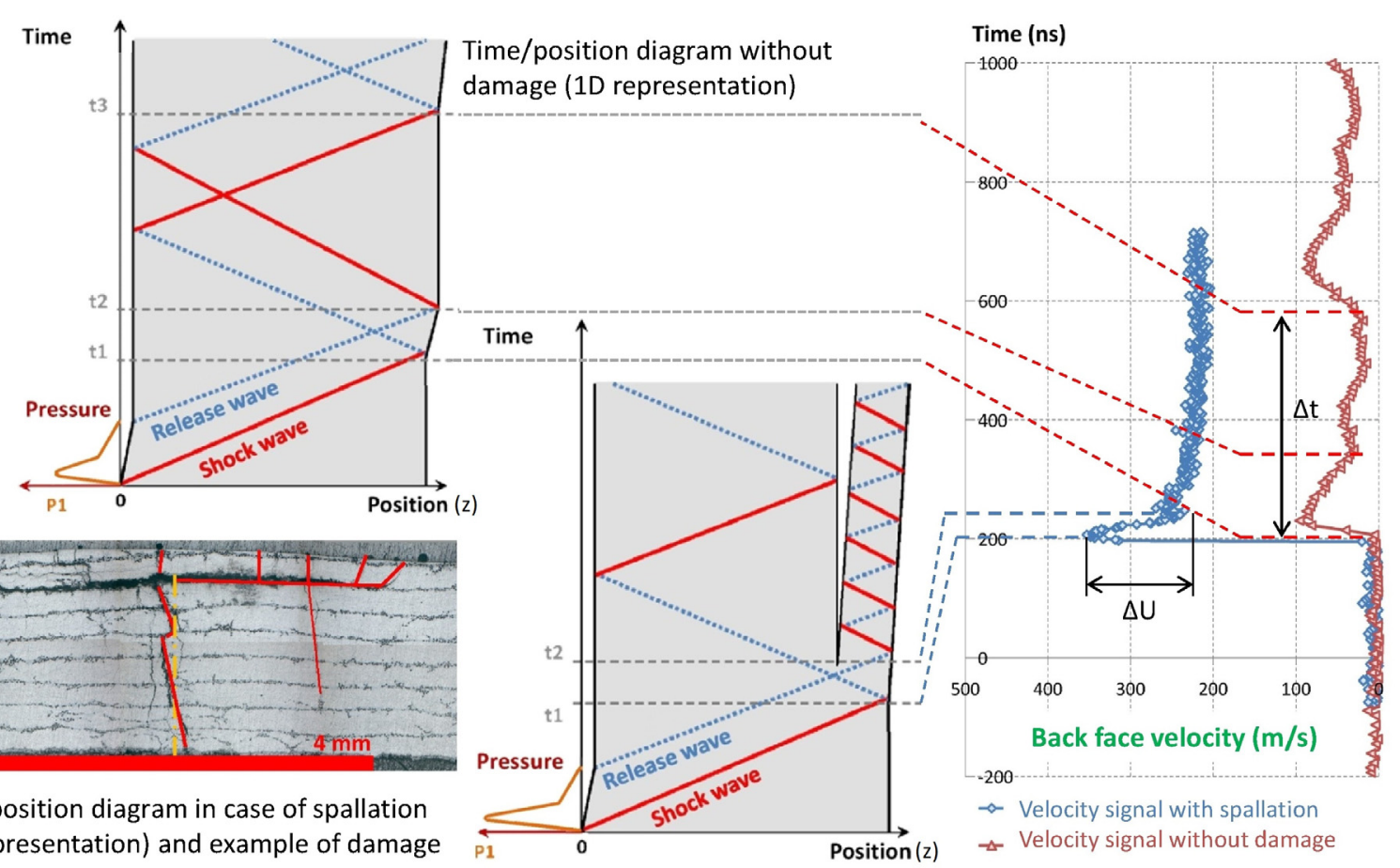

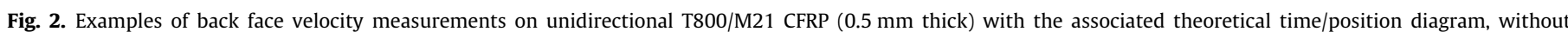
damage and in case of spallation - micrograph of shocked sample ( $2 \mathrm{~mm}$ thick) showing typical damage pattern.

- $2 \mathrm{~mm}$ samples, made of height layers, were used for damage pattern observation. An example is proposed in Fig. 2.

- $3 \mathrm{~mm}$ samples (no polishing) were shocked to provide back face velocity measurement data, also used to compare with modeling in Fig. 8.

Two experimental signals are given in Fig. 2, with their corresponding time/position diagrams. These diagrams are plotted assuming 1D propagation and timing indications are reported from diagrams to free surface velocity chart (on the right side). First case is the one without damage (first diagram on the left). The first event corresponds to the shock breaking-out when the shock front reaches the sample back face. This surface is thus accelerated before being slowed down by the release wave breaking out. Both waves are reflected by the free surface and propagate backward. Tensile stresses are generated but no damage occurs. After one back and forth in the whole target thickness, corresponding to a period of $\Delta t$, a second shock breaking-out occurs. It is characteristic of absence of damage. Indeed, this second shock breaking out cannot be observed in case of spallation (see second diagram in Fig. 2). An opening inside the material would prevent the wave from reaching the target back face one more time. Therefore, a 
measurement on this face cannot record any shock breaking-out if it does not occur. If the pressure is higher, spallation can occur because the induced tensile stresses are stronger. In this case, first event is still the shock breaking-out. The particle velocity is higher since the pressure level is higher. After the pullback induced by the release wave, the matter breaks and the particle velocity oscillates around a constant value. This is a signature of spallation as shown by the time/position diagram. This response is different from the no damage measurement. In case of composite material, spallation means damage. Damage patterns were experimentally evidenced in previous work [24]. It starts with delamination between the plies, followed by matrix cracking especially in the separated plies. Delamination is the most significant damage resulting from laserinduced shock. The higher the pressure, the wider the impacted area. Delamination is generally located close to the back face, and goes deeper inside the target for higher pressure values. As an illustration, a micrograph of a shocked T800/M21 laminate ( $2 \mathrm{~mm}$ thick) is presented in Fig. 2. This typical damage pattern can be observed. Back to the spallation signal, the pullback quantification can lead to a first estimation of the failure stress $\sigma_{Z Z}^{R}$ [49-51]. Estimation is given in Eq. (1), where $\rho_{0}$ is the tested composite density, $c_{0}$ is the speed of longitudinal waves in the $z$ direction of the composite (thickness of the material), and $\Delta U$ is the pullback velocity gap experimentally determined (see in Fig. 2)

$$
\sigma_{\mathrm{ZZ}}=\sigma_{T, m}=\frac{1}{2} \cdot \rho_{0} \cdot c_{0} \cdot \Delta U=0.24 \mathrm{GPa} \text { with }\left\{\begin{array}{l}
\rho_{0}=1580 \mathrm{~kg} / \mathrm{m}^{3} \\
C_{0}=3000 \mathrm{~m} / \mathrm{s} \\
\Delta U=100 \mathrm{~m} / \mathrm{s}
\end{array}\right.
$$

\section{Modeling laser shock experiments}

\subsection{Preliminary steps}

The applied pressure profile for the numerical calculation of laser shock experiments has to be calibrated. The method is based on both experimental measurements by VISAR and numerical calculation of shock propagation for aluminum target. Aluminum is used because its material properties are well-known, and the correlation between laser intensity and induced pressure is well documented in this case $[47,48]$. First, a series of experimental measurements is realized. Laser energy is tuned to produce shock from various pressure levels (see in Fig. 3 - step 1). From this data, one experimental signal is selected to calibrate the pressure temporal profile.

In this purpose, a 1D-model of aluminum is realized. Thickness is equal to $250 \mu \mathrm{m}$, like the physical targets, and a Johnson-Cook law is used to model the hydrodynamic behavior of the target. Parameters can be found in literature [51]. The aim is to obtain a good agreement between the back face velocity measurement and the calculated velocity by using the defined pressure profile. When reached, it means that the pressure profile correctly describes the laser/matter interaction for the experimental configuration. Fitting procedure can be described as follows (see in Fig. 3 - step 2): 1. A pressure temporal profile is drawn. It is based on the temporal laser pulse shape and takes into account the water confinement effect on the pressure pulse duration. 2. This pressure profile is implemented in the model, calculation is performed and numerical back face velocity is compared with the experimental one. 3. According to the comparison made, the pressure temporal profile is adjusted to get a better agreement between the calculated and experimental velocities. 4. By iterative calculations, the best pressure profile is selected. It is the closest one to the experimental signal in terms of amplitude and period (see in Fig. 3 - step 3). 5. Finally, this profile is validated over the whole experimental data, to check that the selected profile averagely matches to all experimental signals (see loop in Fig. 3). Differences can be noticed because of experimental uncertainties, especially for the laser confinement, which can directly influence the pressure load. Nevertheless, this method allows determining the pressure/intensity calibration curve which can be used for composite simulations. Finally, the obtained calibration equation for the used laser source and in our experimental conditions corresponds to previous works $[47,48]$ and is given in Eq. (2). $P$ is the pressure level in GPa, and $I$ is the experimental laser intensity in $\mathrm{GW} / \mathrm{cm}^{2}$.

$P(\mathrm{GPa})=\sqrt{I\left(\mathrm{GW} / \mathrm{cm}^{2}\right)}$

\subsection{Modeling choices}

Regarding the state of the art, anisotropic model should be considered, especially for shock propagation. In this work, focus has been made on elastic models rather than hydrodynamic models. Indeed, these models are still under development. Moreover, it requires material properties and parameters, specific to each modeled composite, and generally not yet available or hard to be obtained. The low pressure used for LASAT, generally under $1 \mathrm{GPa}$, also allows an elastic description regarding other works [52]. For higher pressure, an induced error by this modeling choice should be expected. Speaking of damage, many works address to the use of cohesive law to describe the interlaminar damage propagation or progressive failure. These descriptions are necessary if the aim is the damage extent investigation or the material residual properties after shock. For LASAT applications, where only damage initiation is of interest, damage criteria are enough. Therefore, the Chang/Chang criterion can efficiently be used to model the damage initiation [29,32]. It includes four damage criteria: tensile and compressive failure in fiber direction; tensile and compressive failure in transverse direction. For the laser shock loading, the most important one is the tensile failure in the out-of-plane direction (i.e. matrix damage). It is described in Eq. (3), where e is the criterion value, $\sigma_{Z Z}$ is the out-of-plane stress level, $\tau_{Z X}$ is the shear stress level, $Y T$ and $S C$ are the respective failure stress values. No damage propagation model is particularly implemented. When one of the criteria is met, the corresponding elastic property is set to 0 . The "propagation" goes from an integration point to another due to average stress increase in one element

Tensile failure, inout-of-plane direction : $e_{T, m}^{2}=\left(\frac{\sigma_{Z Z}}{Y T}\right)^{2}$

$$
+\left(\frac{\tau_{Z X}}{S C}\right)^{2}-1\left\{\begin{array}{l}
\geqslant 0 \text { failure } \\
<0 \text { elastic }
\end{array}\right.
$$

This is the damage criterion implemented in MAT_022_COMPOSITE_DAMAGE, available in LS-DYNA (LS-PREPOST software), with an orthotropic elastic behavior [30,31]. It is thus well adapted to the modeling of composite ply. The material model axes are always initially collinear to the global system axes, taking $x$ direction for fiber, $y$ direction for the transverse in-plane direction, and $z$ direction for the out-of-plane direction thus corresponding to the loading axis. Therefore, the tensile stresses generated by the laser shock wave always correspond to $\sigma_{\mathrm{Zz}}$. As shown by the literature overview, one of the key points for composite material modeling is to use the appropriate material parameters. Initial parameters are given in Table 1. These are quasi-static parameters from literature. For each parameter, two names are given: the one used by LS-PREPOST software in the material card, and the name corresponding to the abbreviations used in this work. Some parameters are redundant due to modeling choice.

Interfaces, between two composite plies or between a composite and the bond layer, have been modeled by using 


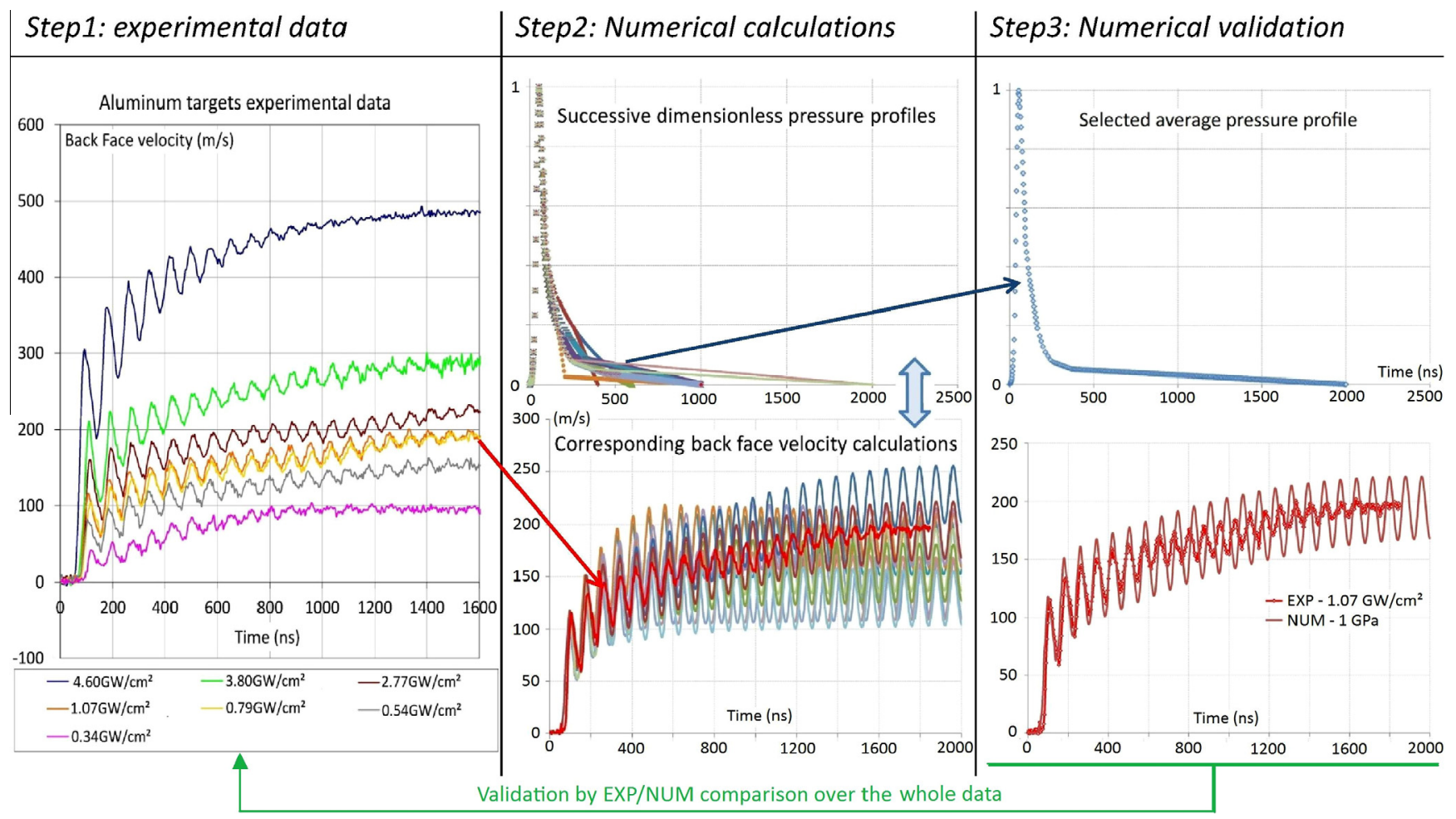

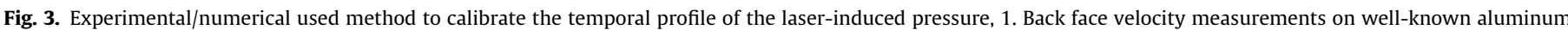
targets, 2 . Adjustment of the numerical profile to one of the experimental curve by successive calculations, 3 . Profile validation over the whole experimental data.

Table 1

T800/M21 orthotropic ply quasi-static properties (elastic and damage parameters) from different sources; Airbus data sheet (a), literature [27-29] (b) and calculated from literature (c)

\begin{tabular}{|c|c|c|c|c|}
\hline $\begin{array}{l}\text { LS- } \\
\text { DYNA }\end{array}$ & Abb. & Parameters & Values & Source \\
\hline \multicolumn{5}{|c|}{ Elastic properties } \\
\hline RO & $\rho$ & Density & $\begin{array}{l}1.58 \mathrm{~g} / \\
\mathrm{cm}^{3}\end{array}$ & (a) \\
\hline EA & $E_{x x}$ & Tensile modulus in fiber direction $x$ & $165 \mathrm{GPa}$ & (a) \\
\hline EB & $E_{y y}$ & $\begin{array}{l}\text { Tensile modulus in the transverse } \\
\text { in-plane direction } y\end{array}$ & $8.5 \mathrm{GPa}$ & (b) \\
\hline EC & $E_{z z}$ & $\begin{array}{l}\text { Tensile modulus in the transverse } \\
\text { out-of-plane direction } z\end{array}$ & $8.5 \mathrm{GPa}$ & (b) \\
\hline PRBA & $v_{y x}$ & Poisson coefficient $y x$ & 0.02 & (c) \\
\hline PRCA & $v_{z x}$ & Poisson coefficient $z x$ & 0.03 & (c) \\
\hline PRCB & $v_{z y}$ & Poisson coefficient $z y$ & 0.035 & (c) \\
\hline GAB & $G_{x y}$ & Shear modulus in $x y$ plane & $4.2 \mathrm{GPa}$ & (b) \\
\hline GBC & $G_{y z}$ & Shear modulus in $y z$ plane & $2.7 \mathrm{GPa}$ & (b) \\
\hline GCA & $G_{z x}$ & Shear modulus in $z x$ plane & $4.2 \mathrm{GPa}$ & (b) \\
\hline \multicolumn{5}{|c|}{ Damage parameters } \\
\hline $\mathrm{SC}$ & $\sigma_{S}$ & Interlaminar shear strength $\left(0^{\circ}\right)$ & $110 \mathrm{MPa}$ & (a) \\
\hline XT & $\sigma_{T, f}$ & $\begin{array}{l}\text { Tensile strength in the fiber direction } \\
\left(0^{\circ}\right)\end{array}$ & $2800 \mathrm{MPa}$ & (a) \\
\hline YT & $\sigma_{T, m}$ & $\begin{array}{l}\text { Tensile strength in the transverse } \\
\text { direction (matrix) }\end{array}$ & $110 \mathrm{MPa}$ & (b) \\
\hline YC & $\sigma_{C, m}$ & $\begin{array}{l}\text { Compressive strength in the transverse } \\
\text { direction (matrix) }\end{array}$ & $200 \mathrm{MPa}$ & (b) \\
\hline SN & $\sigma_{T, i}$ & $\begin{array}{l}\text { Tensile strength in the direction } \\
\text { normal to elements/interlaminar } \\
\text { tensile strength }\end{array}$ & $110 \mathrm{MPa}$ & (b) \\
\hline SYZ & $\sigma_{S, Y Z}$ & Shear strength in the $Y Z$ plane & $110 \mathrm{MPa}$ & (b) \\
\hline SZX & $\sigma_{S, Z X}$ & Shear strength in the $Z X$ plane & $110 \mathrm{MPa}$ & (b) \\
\hline
\end{tabular}

AUTOMATIC_SURFACE_TO_SURFACE_TIEBREAK law. It is a specific LS-DYNA law, well adapted to composite material. This interface modeling enables to initially put two interfaces in contact, and includes damage criterion. Option 6 has been chosen to correctly represent the damage initiation. This law uses a unique failure criterion, taking into account two damage parameters respectively in tension and shear. It is described in Eq. (4). The directions are defined regarding the normal to the interface, and values are equal to the composite material model ones. Once the criterion is reached, the interface strength is progressively decreased. A parameter, named PARAM, provides the slope of this progressive interface damage.

$\left(\frac{\left|\sigma_{n}\right|}{\text { NFLS }}\right)^{2}+\left(\frac{\left|\sigma_{s}\right|}{\text { SFLS }}\right)^{2} \geqslant 1\left\{\begin{array}{l}\sigma_{n}: \text { Tensile stress, NFLS : tensile strength } \\ \sigma_{s}: \text { Shear stress, SFLS : shear strength }\end{array}\right.$

The laser-induced pressure is directly applied on the model front face. Technically, this is done by using the validated temporal pressure profile, obtained during the calibration step. A load is then applied on a set of segment representing the laser irradiation spot. This is a circular area in case of 3D modeling, and a single strip in case of 2D models. In order to avoid strong nonphysical shear on the pressure area edges, smoothing has been introduced. Linear decrease has been applied on the pressure value over the last $0.09 \mathrm{~mm}$ of each edge. Mesh size has been set to $10 \mu \mathrm{m}$ to enable correct shock wave propagation through the whole model, without any loss of information. Mesh sensitivity has been checked.

Note that "3D" and "2D" models have successively been used (see models in Fig. 4). 3D model was representing a quarter of unidirectional composite material, solution being possible thanks to axisymmetry (see Fig. 4a). It has been used for parameter identifications (see next section). On the other hand, quantitative comparisons have shown that a reduction to a "2D slice" was possible (see Fig. 4a). It is due to the fact that the shock wave mainly propagates in the out-of-plane direction. Therefore, to save calculation time, 2D models have been used to simulate the tested composite materials. Each model is a slice of solid elements, required for the composite modeling, 


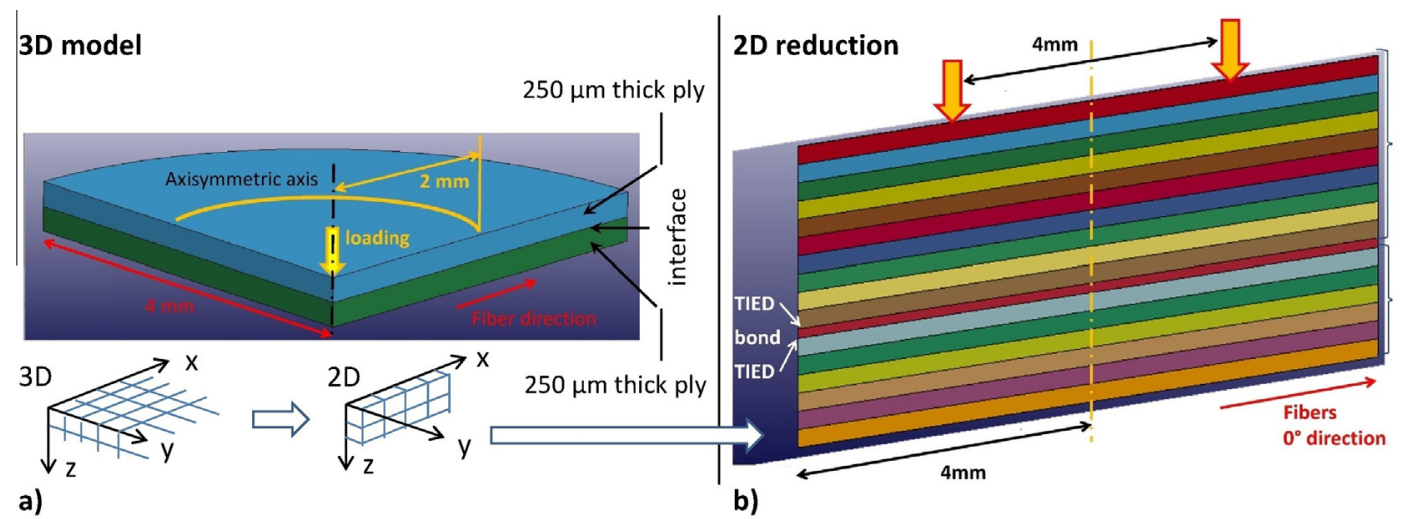

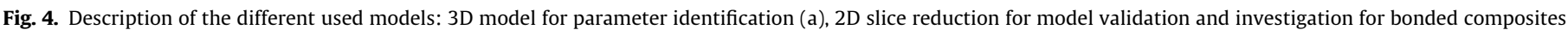
(b).

with the appropriate boundary conditions. An example for bonded composites is given in Fig. $4 \mathrm{~b}$.

\section{Numerical results for CFRP}

\subsection{Parameter identification}

The parameter identification stands for a preliminary study of laser shock modeling dedicated to composite. Purpose is here to identify the correct parameters for the model. Indeed, elastic features of composite material, presented in Table 1, can be modified by high strain rate. As explained, this is the case of laser shock loading. For that, three steps are necessary: 1. Identification of the influent parameters, 2. Identification of the elastic constants, 3. Adjustment of the damage thresholds.

In this section, the used back face velocity data has been obtained with $0.5 \mathrm{~mm}$ unidirectional T800/M21 composite (2 plies). For these calculations of laser shock on composite, the pressure level is evaluated with the intensity/pressure correlation previously described. However, note that a correction factor about 0.7 has to be used to take into account the fact that aluminum painting is used, and not pure aluminum. This correction factor have been evaluated using one experimental signal, and confirmed thanks to the whole experimental data like for the material parameters.

\subsubsection{Identification of the influent parameters}

The most influent parameters on the CFRP dynamic response have been determined thanks to a numerical parametric study. Most significant results are presented in Fig. 5. This figure presents several back face velocity curves (see velocity curve meaning in Fig. 2). For this study, the 3D model is used (see in Fig. 4). The pressure level is arbitrary chosen low enough ( $0.1 \mathrm{GPa})$ to be far from the damage thresholds, leaving damage investigations for a next step. The reference signature, i.e. the reference velocity curve, is the one obtained using the quasi-static parameters given in Table 1. For this study, it is considered as the initial response, and noted using "ini" subscript. Then, parameters are tuned one by one, all other parameters being the same, to estimate their influence on the numerical CFRP response. Results for various fiber moduli are presented in Fig. 5a), and various outof-plane modulus ones are given in Fig. 5b). Reference curve is added on both charts. Results show different effects of each parameter. Fiber modulus acts on the secondary order phenomenon, named anisotropic bouncing. It plays on its timing. For really high values (factor 10), fiber modulus increases attenuation, as shown by the amplitude drop (see in Fig. 5a). Out-of-plane modulus also has an influence on the attenuation although it is more linear than in the case of fiber modulus (see in Fig. 5b). Moreover, it has a strong effect on the wave back and forth period. Both observations are consistent with theory because transverse sound celerity is correlated to the transverse modulus. It is also logical since shock wave mainly propagates in the out-of-plane direction. With these results, effects are quantified.

\subsubsection{Identification of the elastic constants}

Strong from the previous results, model parameters can now be tuned to fit one experimental signal, knowing that the most important parameters are Young's modulus values in the three directions. For that, several calculations with various modulus values are iteratively performed to fit one back face velocity signal, randomly selected in the experimental data range. Fitting procedure can be shortly described as follows. Starting point being the elastic constants (see Table 1), Young's modulus values are increased until obtaining a correct fitting between numerical calculation and the experimental signal. The first parameter to be varied is the one which influences the most the back face velocity signal, namely the out-of-plane modulus as shown by the parametric study (see in Fig. 5b). It fits the back and forth period. The transverse inplane modulus is taken equal to the out-of-plane modulus, as usual for orthotropic material. The fiber direction modulus is then chosen to fit second order velocity variations. Iterative calculations are performed to obtain the best fitting. Result is given in Fig. 6 1 st step. On the left, numerical and experimental back face velocities are compared. Looking to these curves, it can be observed that agreement is quite good, thus showing that the elastic constant are correct.

\subsubsection{Adjustment of the damage thresholds}

In a second time, the damage parameters to the laser shock strain rate have to be adapted. In this purpose, the first - meaning the lowest energy one - experimental signal showing a clear spallation signature is used. Since the experimental data is complete enough, it is assumed that this signal has been obtained for a pressure close to the threshold pressure leading to damage. Fitting is presented in Fig. 6 - 2nd step. Here again, comparison between experiment and calculation is good in terms of velocity amplitude, and velocity pull-back value.

The proposed modifications of the parameters are summarized in Eq. (5): subscript $D$ indicates dynamic parameter values, and subscript $Q S$ corresponds with quasi-static parameter values. 

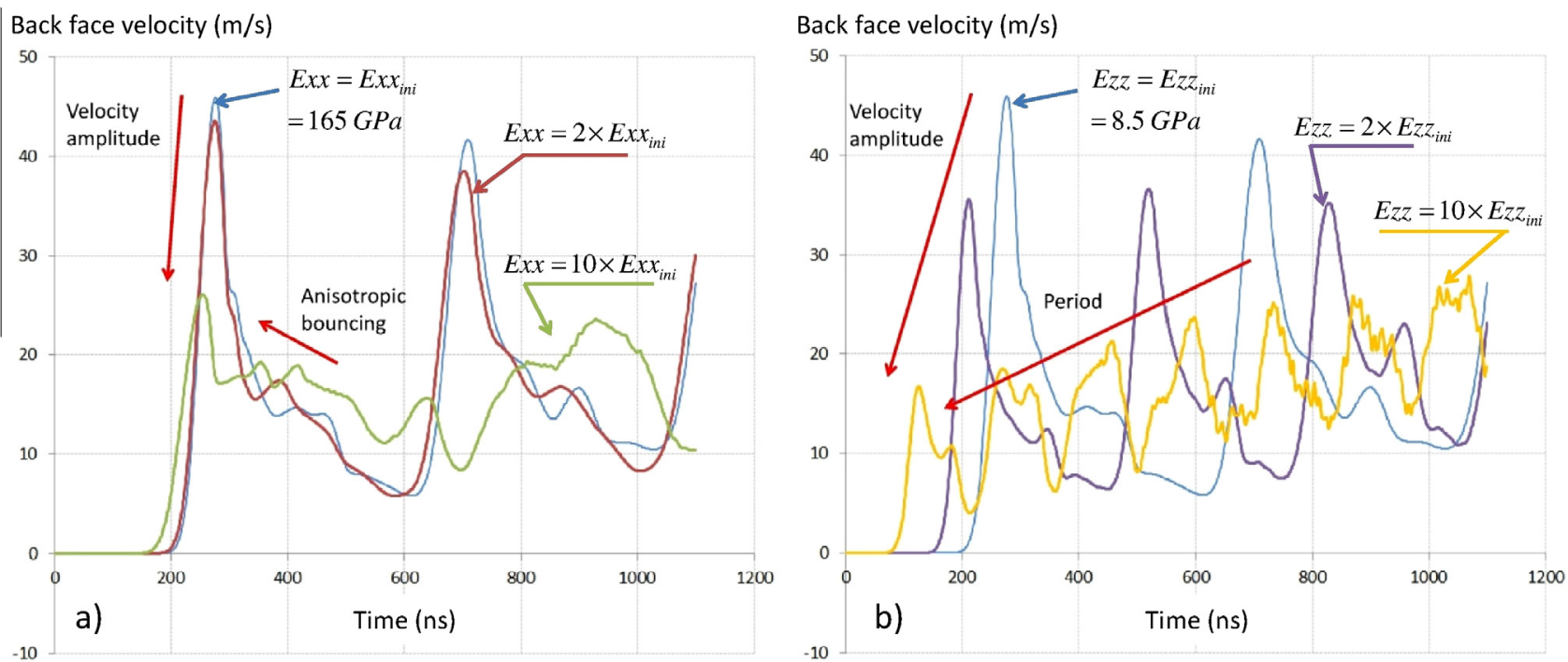

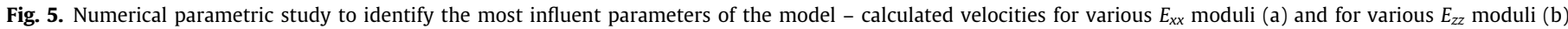
starting from the quasi-static values - T800/M21, 2 plies, $500 \mu$ m thick, 3D model (Fig. 4) input pressure 0.1 GPa (Fig. 3).

\section{Thin $(0.5 \mathrm{~mm})$ unidirectional T800/M21 composite modeling}
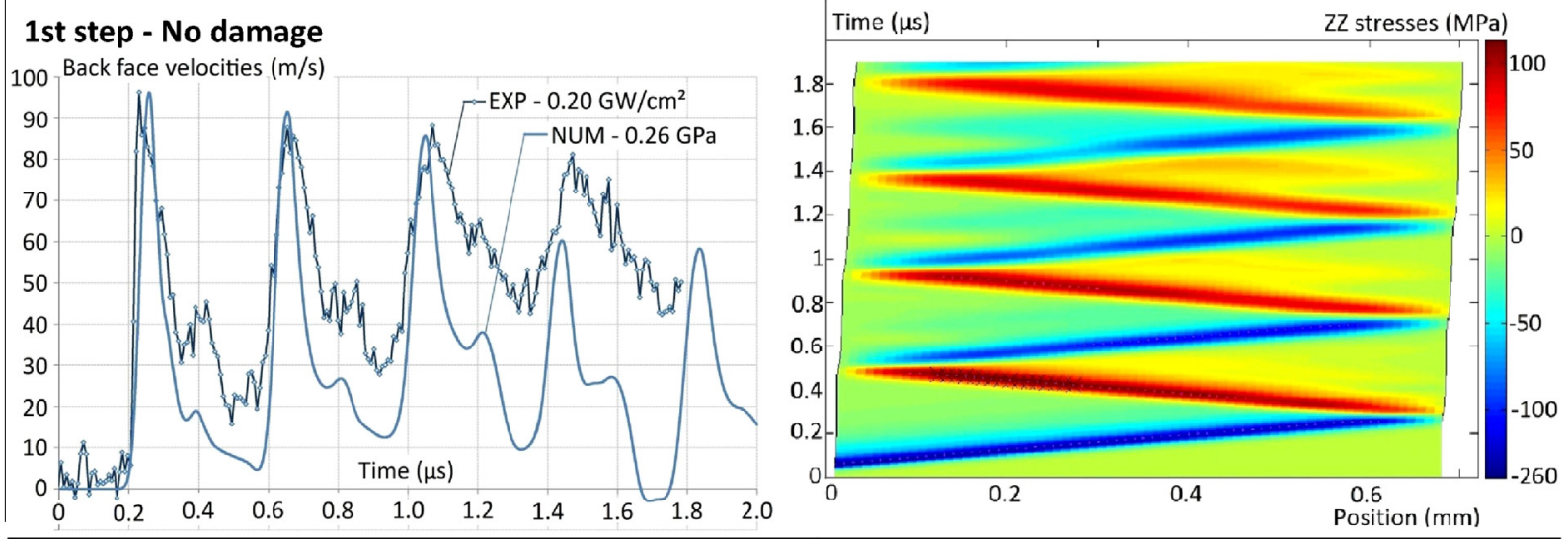

\section{2nd step - With damage}
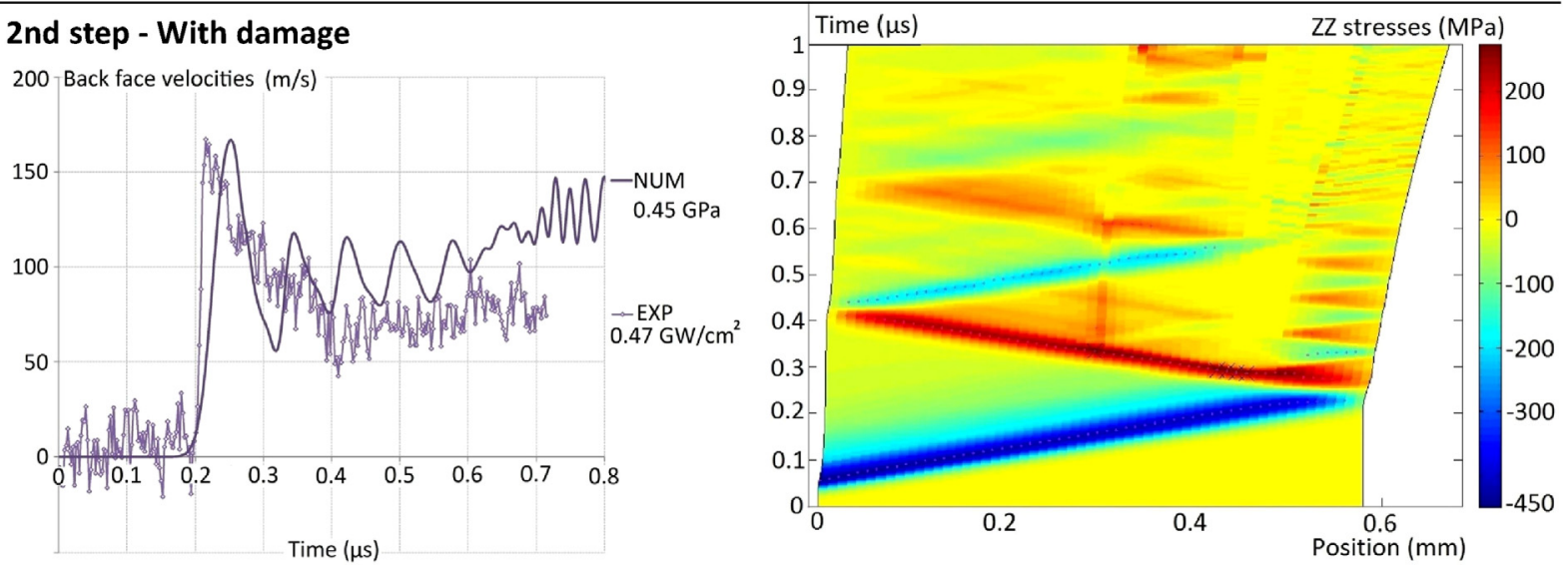

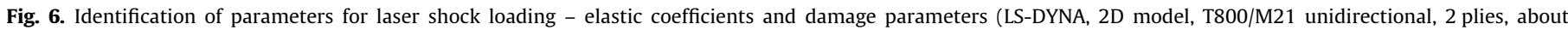
$500 \mu \mathrm{m})$.

Transverse modulus is 1.7 time higher, fiber modulus is 2 times higher, and damage parameters are increased using a 2.5 factor. These values have been determined using two experimental signals. Once they have been identified, these exact same parameters have to be validated by comparing other calculation cases to the other experimental signals, and covering the whole experimental range. This way, identified parameters can be trusted (see model validation section)

$$
\left\{\begin{array}{l}
E z_{D}=1.7 \times E z_{Q S}, \quad E y_{D}=1.7 \times E y_{Q S} \\
E x_{D}=2 \times E x_{Q S} \\
(\text { damage parameters })_{D}=2.5 \times(\text { damage parameters })_{Q S}
\end{array}\right.
$$




\subsubsection{Comments and discussions}

Physical meaning of the signals can be first discussed. For that, a time/position diagram is given on the right of Fig. 6 for both cases. It has been obtained using a homemade Matlab post-treatment tool. It gives the stresses distribution through the composite thickness and along the loading axis. Below the spallation threshold, the absence of damage is confirmed by the observation of several back and forth periods. Indeed, if a delamination occurs during the wave propagation, the velocity signal will change due to a change in the material impedance/geometry.

In comparison, the signal with spallation is different. Experimentally, the generated tensile stress within the composite laminate led to delamination, and then to matrix cracking in the delaminated plies [24]. Numerically, the tensile criterion is reached in the laminates (see Eq. (3)), and probably at the interface also (see Eq. (4)). Oscillations which can be observed after the damage initiation has a physical meaning as shown by the time/position diagram. It corresponds to the wave back and forth in the separated thickness of the composite material. They are more visible for the calculation than for experiment because of the damage modeling, which is simple, and a bit far from the real damage propagation. This good agreement has been obtained with tensile and shear strength values set to $275 \mathrm{MPa}$. It is close from the value experimentally estimated about $240 \mathrm{MPa}$ (see Eq. (1)). Difference can be due to modeling hypotheses of course, but also to the available experimental data which may not be right on the threshold.

More generally, experimental to numerical differences which can be observed are mainly due to the pressure temporal profile, which has been averagely estimated. Indeed, only one numerical pressure profile is used (see in Fig. 3), when practically, each shock is slightly different. Anyway, the important point is to finally get a good agreement for the whole data, and thus validate the model (see Figs. 7 and 8).

\subsection{Model validation}

First validation step is to compare the numerical results to the complete experimental data of $0.5 \mathrm{~mm}$ T800/M21 unidirectional composite material. The composite model parameters are kept identical to the ones previously identified. Results are given in Fig. 7. Signals with and without damage are presented. The lowest-energy signal is below the pressure level presented in Fig. 6. It shows a good agreement in terms of back face velocity amplitude, and also for the back and forth period. The other three couples of signals have been obtained for a higher pressure than for the one presented in Fig. 6. It is therefore logical that damage occurs, as shown by the particular spallation signature. Agreements between experiments and calculations are thus correct.

In a second time, the model has been validated using a second set of experimental data. This data has been obtained for $3 \mathrm{~mm}$ thick T800/M21 unidirectional composite (12 plies). Results are presented in Fig. 8, without damage (a), and with damage (b). Comparisons are quite good. For the two signals without damage, the back and forth period is well reproduced by the numerical calculations. Moreover, the second order velocity peaks are also well described. These peaks are mainly due to composite orthotropic characteristics. It shows that the model correctly describes this thick composite dynamic response to laser shock. Finally, signals with damage are compared in Fig. 8b. Here again, results show that the dynamic damage parameters have been correctly adjusted. Indeed, the first experimental signal showing a spallation signature is correctly restituted by the numerical calculation. Moreover, the shock breaking-out induced velocity is correctly calculated, and this is the case for all the signals. It proves that the pressure/intensity law is correct. The damage model limitations are also visible for thick composite. Indeed, higher the pressure is, sooner the deviation in the spall velocity occurs. As explained, a correct description of this behavior was not targeted, important point being damage initiation. Therefore, thanks to these good results for thin and thick T800/M21 composite material, the composite model is validated.

Before reaching the bonded assembly results, note that the model of the bond epoxy has also been validated before being used in the bonded composite model. Results are not described in this paper, but some information about the modeling of epoxy materials can be found in other published work [53].

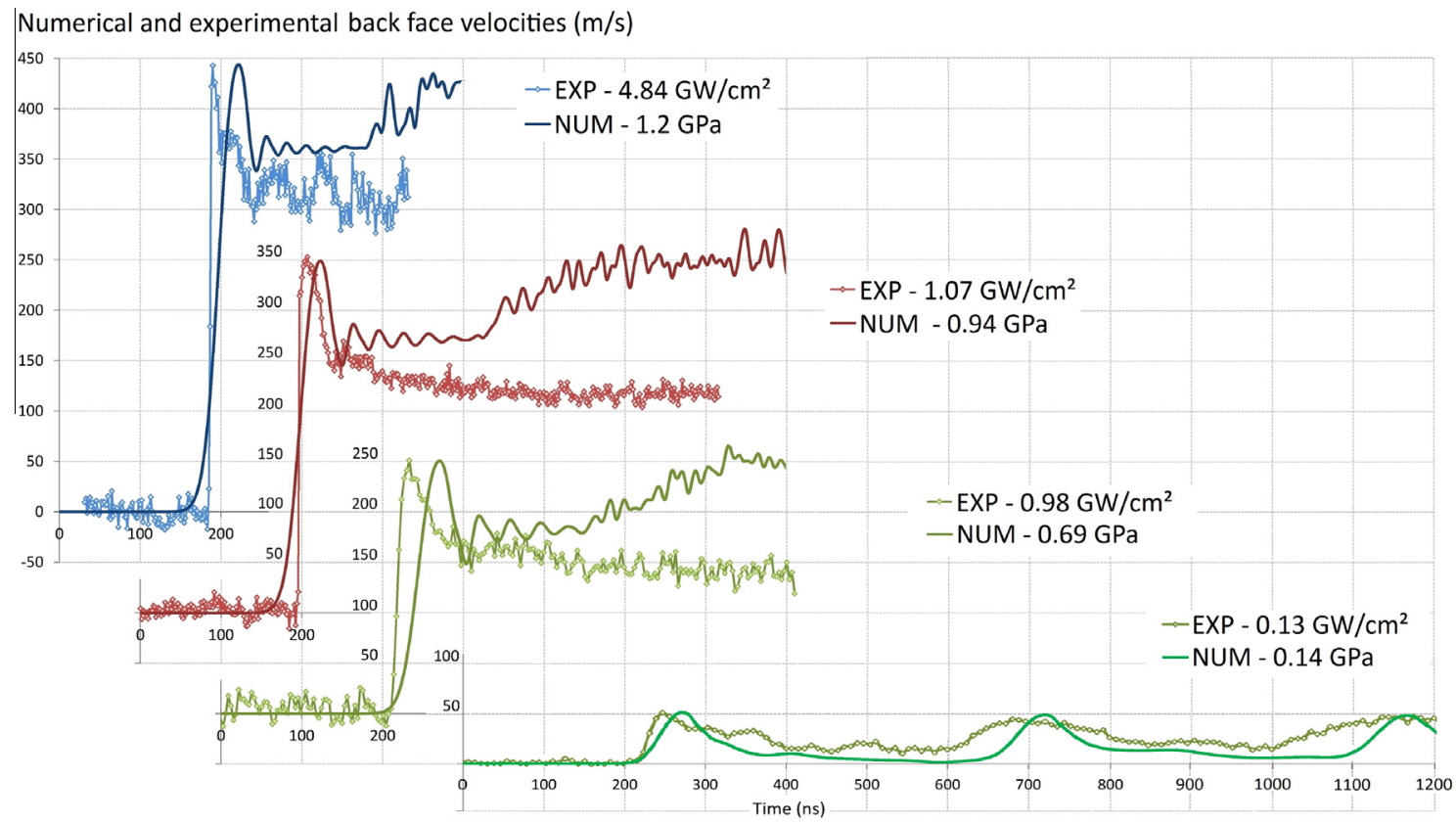

Fig. 7. Model validation in case of thin T800/M21 unidirectional, 2 plies, $500 \mu \mathrm{m}$ thick, with and without damage (LS-DYNA, 2D model). 

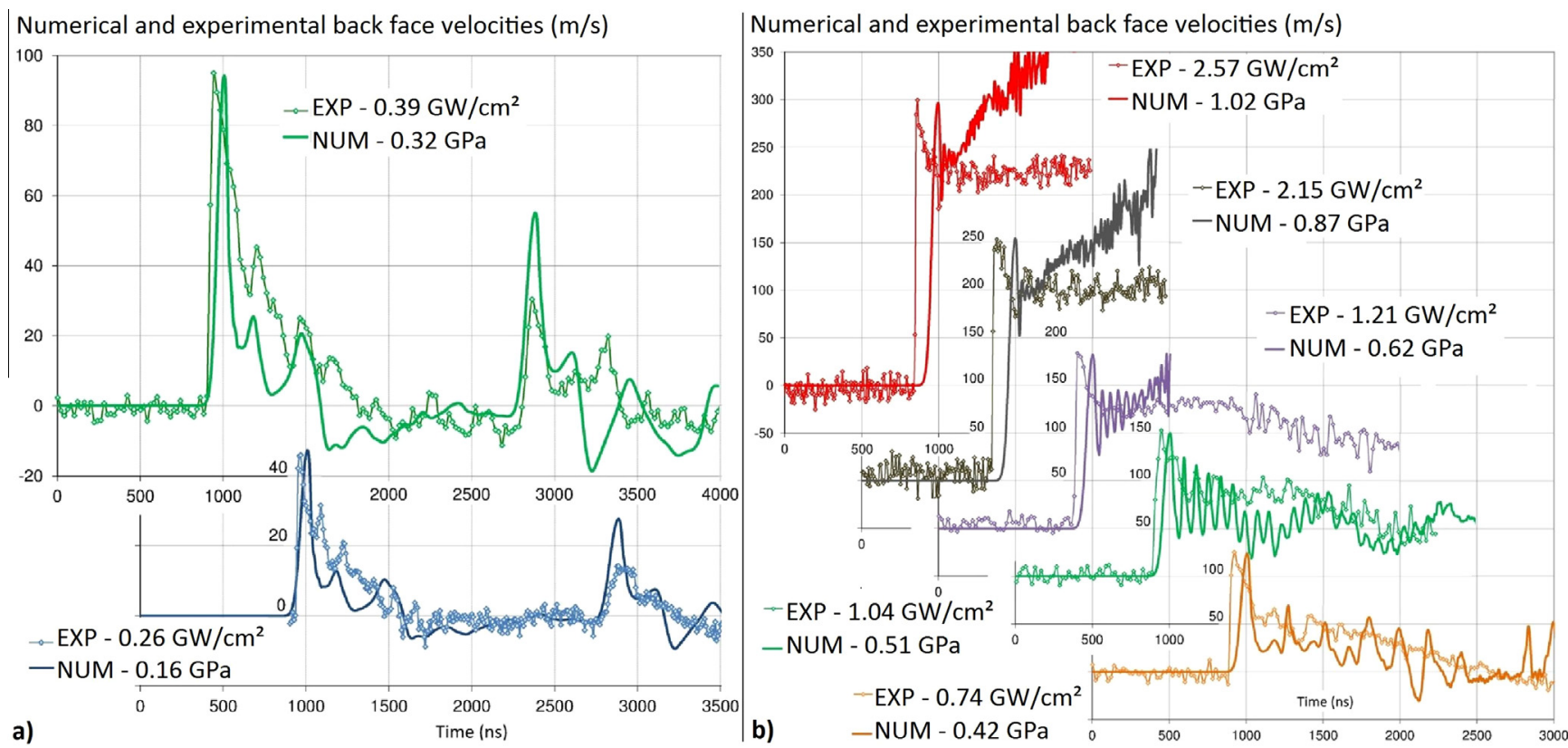

Fig. 8. Model validation in case of thick T800/M21 unidirectional, 12 plies, $3 \mathrm{~mm}$ thick, with (b) and without (a) damage (LS-DYNA, 2D model).

\section{Numerical results for bonded composites}

The numerical results given in this section have two main goals. First, it enables to validate the bonded assembly numerical model, and then, it can be used as a tool to reach a better understanding of the shock propagation.

To present and explain both ideas, the example of a T700/M21 bonded assembly is taken. This assembly is made of two composite laminates: one is $2.5 \mathrm{~mm}$ thick, with the following stacking sequence $[0,0,90,90,0,0,90,90,0,0]$, the second is $1.5 \mathrm{~mm}$ thick, with a $[0,0,90,90,0,0]$ lay-up. A FM300 epoxy adhesive film is used to bond the two composite laminates. Its thickness is equal to $130 \mu \mathrm{m}$. It corresponds to a classic aeronautic bonded system. For this assembly, experimental data and numerical results have been obtained in this work. Note that the bonded assembly model is made from the results of the previous model, with a 2D slice reduction (Fig. 4b). In Fig. 9, numerical results and experimental data are given together and displayed in three zones. This

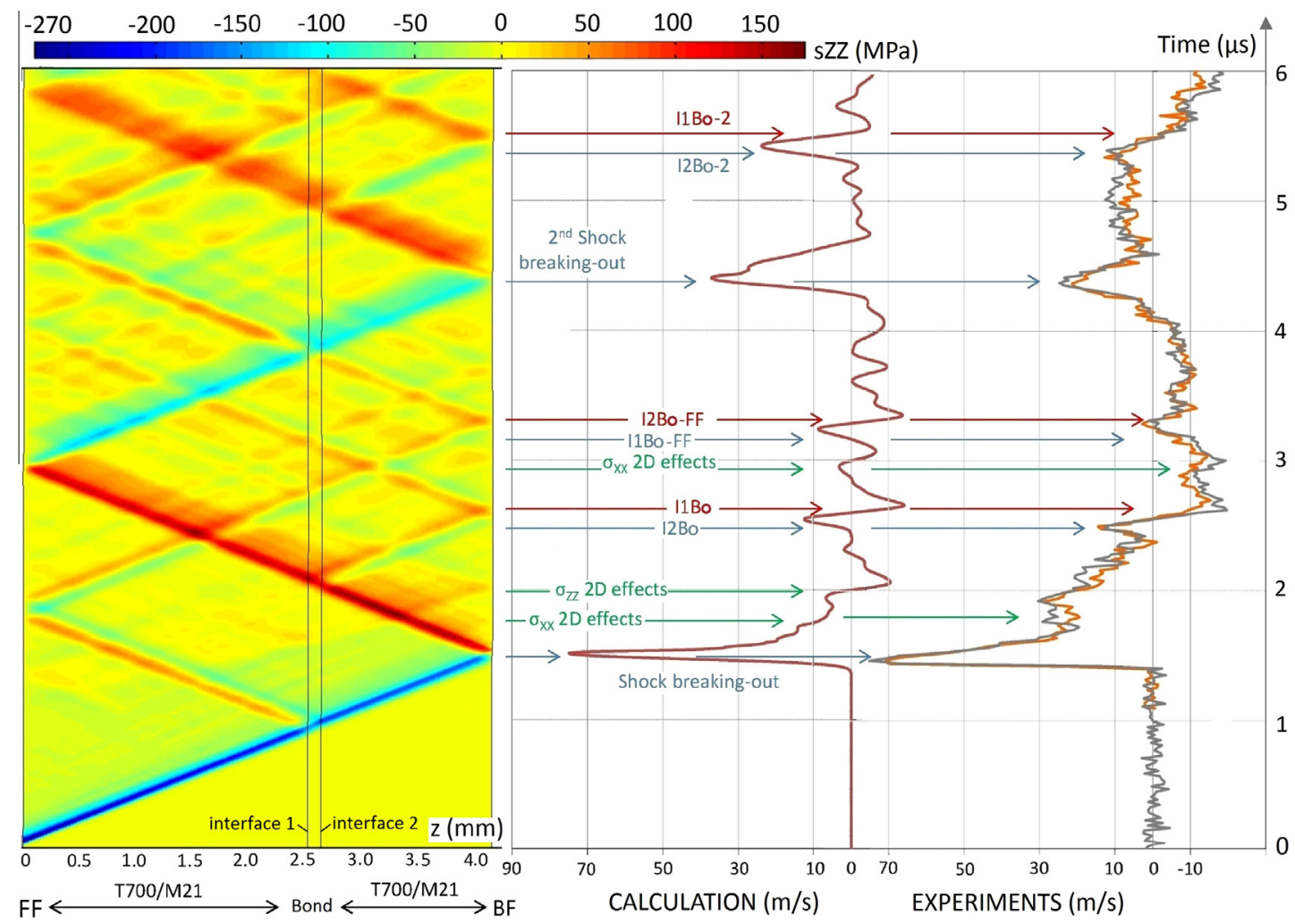

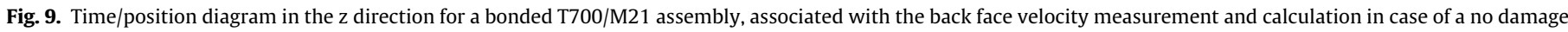
shock $(0.27 \mathrm{GPa})$ - Identification of the different peak origins helped by the numerical modeling. 
representation enables to draw links between the experimental results and the numerical ones. On the left side, a time position diagram is given. It gives the $\sigma_{Z z}$ stress distribution within the thickness of the bonded composites during the shock wave propagation. It is observed being collinear with the loading axis (see Fig. 4). In the middle, the corresponding calculated back face velocity is given. Time axis is vertical, and velocity amplitude axis is horizontal to enable a common reading of the two charts. Using the same display, two experimental signals obtained from laser shock experiments are given on a third chart, placed on the right. Note that the amplitude of the numerical pressure profile has been adjusted to correspond to the given experimental cases (same pressure for both). Moreover, the induced stresses are below the damage threshold of the composite laminate.

First, the good comparison between the calculated back-face velocity and the experimental ones should be commented. Indeed, agreement is quite good as shown by the good matching of each velocity pattern. In Fig. 9, arrows help the reading between numerical signal and experimental one. If timing is almost perfect, some differences can be noticed on the peak amplitude after one back and forth. This is mainly due to 2D modeling choice. A full 3D model would have a stronger softening potential. Nevertheless, this good agreement between experiment and calculation enables to fully validate the numerical model. Numerical description of the phenomenon can be trusted to better understand the shock wave propagation in this complex assembly.

For that, time/position diagram and the corresponding back face velocity can be used (see in Fig. 9). Arrows from the diagram to the back-face velocity are used to track the origin of each velocity peak. For a clear understanding, Fig. 9 should be read with Table 2, where are given the significations for each referred arrow. Complex velocity signals such as this one can now be explained and understood. Note that each transmission/reflection phenomenon identified on this chart is consistent with the shock theory in terms of impedance mismatch.

Back to the laser shock wave adhesion test, these numerical results considerably help the development of the technique. Taking as example the case presented in Fig. 9, the tensile stresses reaching the bond interface can be quantified, about $100 \mathrm{MPa}$ here. Since modeling fairly represents the physical shock propagation, it means that the strength of the physical bonded sample can also be quantified.

Investigations can be pushed forward to estimate if the used laser source is well adapted to laser shock adhesion test for such bonded assemblies. The characteristics of the source used in this work are given in Fig. 1. For laser shock adhesion test, most important parameters are pulse width and energy. The energy set the pressure level and the pulse width influences the stress distribution $[21,25,26]$. Laser pulse width is about $25 \mathrm{~ns}$, which means that the pressure pulse is about 50 ns for water-confined configuration (see Fig. 3) $[47,48]$. The induced stress distribution by this particular pulse might not be adapted to adhesion test of the T700/M21 bonded assembly presented in this study. To check that, numerical calculation and laser shock experiments have been performed above the damage threshold of the composite laminate. If the physical bond was a good one, the numerical interfaces between the laminates and the bondline were set to be identical to the composite interlaminate interfaces. That and the pressure level are the only differences with the presented results in Fig. 9. Experimental and numerical results are given in Fig. 10. Here again, two experimental signals are given to check reproducibility. Matching with numerical calculation is good in terms of timing and amplitude, which validates one more time the modeling choices. These signals clearly evidence a spallation phenomenon. A change of frequency traduces the waves going back and forth in the separated spall. The absence of the second shock breaking-out also demonstrates that delamination has occurred in the assembly during the wave propagation. The time/position representation highlights where the damage occurred. It is located between the two $0^{\circ}$ plies, and the two $90^{\circ}$ plies. Indeed, the composite damage threshold is first overpassed at this depth in the material, leading to damage. This position has been confirmed by post-mortem observation of the tested bonded assembly (see Fig. 10, on the right). The observed damage is highlighted by white lines in the shown micrograph. This damage dissipates energy, but the tension wave still propagates backward. Nevertheless, numerical results show that the remaining tensile stresses were not high enough to separate another interface such as the bondline/interface one. It is confirmed by the absence of disturbance of the second shockwave (after tension wave reflection on front face) until the delaminated depth. Consequently, it can be observed that the used pulse is not well adapted to test this assembly. First stresses, and maximal stresses, are located in the back-face composite laminate, where the damage occurs first if the pressure is increased. Test cannot be non-destructive in this case. Therefore, next step is now to use this reliable numerical model to define the appropriated shock configuration for testing this assembly, and to develop the corresponding laser source set-up.

Table 2

Back face velocity peaks origins according to their timing position.

\begin{tabular}{|c|c|}
\hline Notations & Origin explanation \\
\hline 1st shock Breaking-out & Back face velocity peak corresponding to the shock wave breaking-out and reflection on the free surface \\
\hline$\sigma_{X X} 2 D$ effects & $\begin{array}{l}\text { Fiber anisotropic effects. Indeed, the small bouncing evidenced on the main release slope is generated by a } \sigma_{X X} \text { stress concentration at } \\
\text { the free surface (not displayed here) }\end{array}$ \\
\hline$\sigma_{Z Z} 2 \mathrm{D}$ effects & $\begin{array}{l}\text { Focal spot edge effects, also named } 2 \mathrm{D} \text { effects in other works [51]. It corresponds to a } \sigma_{Z Z} \text { stresses concentration, correlated to the focal } \\
\text { spot size. It leads to an important decrease in the back face velocity }\end{array}$ \\
\hline I2Bo & $\begin{array}{l}\text { Interface } 2 \text { bouncing - velocity bouncing induced by the compression wave coming from the reflection of the main tension wave } \\
\text { propagating backward on the second bond interface }\end{array}$ \\
\hline I1Bo & $\begin{array}{l}\text { Interface } 1 \text { bouncing - velocity decrease immediately following I2Bo and induced by the tension wave coming from the reflection of the } \\
\text { main tension wave propagating backward on the first bond interface }\end{array}$ \\
\hline$\sigma_{X X} 2 \mathrm{D}$ effects & This bouncing does not seem to be due to a transmission/reflection phenomenon. Therefore, it could be attributed to an anisotropy effect \\
\hline I1Bo-FF & $\begin{array}{l}\text { Interface } 1 \text { bouncing - from front face. Induced by the compression wave coming back from the front face after a first reflection of the } \\
\text { shock wave at the } 1 \text { st bond interface. The shock is reflected into a tension wave propagating backward at the first bond interface. This } \\
\text { wave is itself reflected into a compression wave after reaching the front face }\end{array}$ \\
\hline I2Bo-FF & $\begin{array}{l}\text { Interface } 2 \text { bouncing - from front face. Induced by the tension wave coming back from the front face after a first reflection of the shock } \\
\text { wave at the } 2 \text { nd bond interface. Indeed, the shock is reflected into a compression wave propagating backward at the second bond } \\
\text { interface. This wave is itself reflected into a tension wave after reaching the front face }\end{array}$ \\
\hline 2nd shock breaking-out & 2nd back face velocity peak corresponding to the shock wave breaking-out after a back and forth \\
\hline I2Bo-2 & Interface 2 bouncing - 2nd release. Similar to I2Bo, after back and forth \\
\hline I1Bo-2 & Interface 1 bouncing - 2nd release. Similar to I1Bo, after back and forth \\
\hline
\end{tabular}



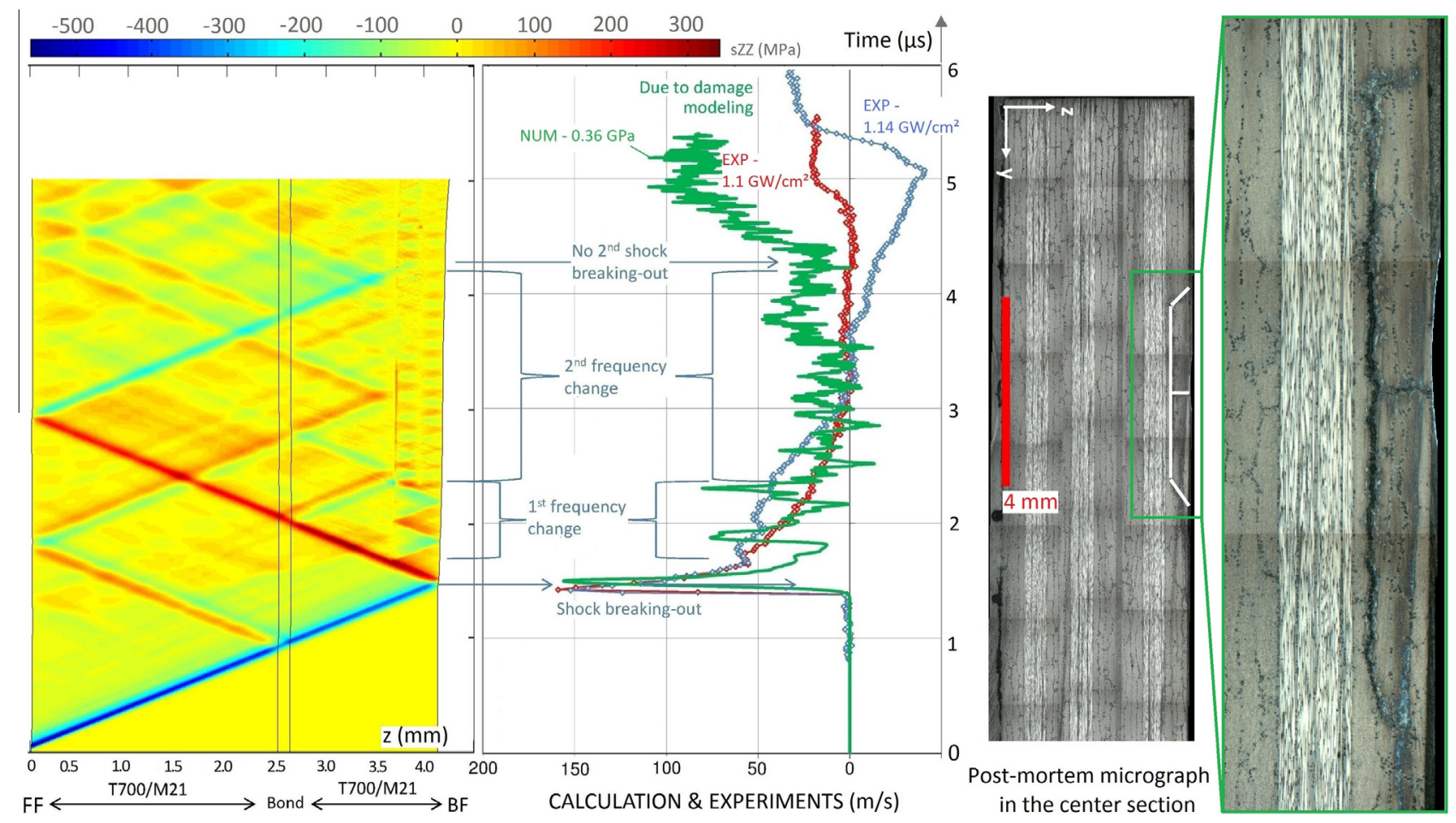

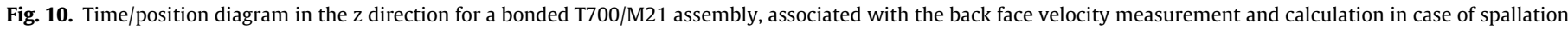
$(0.56 \mathrm{GPa})$ - identification of the different peak origins helped by the numerical modeling.

\section{Conclusions}

In this work, focus was made on the development of a reliable numerical model of bonded composites under laser shock loading. Objective was to provide a numerical tool to help the optimization of the laser shock wave adhesion test, whose final target is to propose a solution for composite bonding assessment. Both experimental and numerical results were obtained.

\subsection{Experimental results}

Laser shock experiments were conducted on various CFRP, namely T800/M21 composite laminates, and T700/M21 bonded composite

- Their dynamic responses to laser shock loading have been studied and quantified using time resolved measurements and postmortem analysis. Back face velocity measurements have shown the material mechanical response, and enabled to estimate a spallation threshold, i.e. a dynamic delamination threshold, about $240 \mathrm{MPa}$. These experiments have also provided data for the numerical model development and validation.

- Post-mortem inspections have revealed the damage patterns resulting from the laser-induced shock. Spallation is characterized by ply delamination, and matrix cracking within the delaminated plies. These inspections have been shown to be consistent with the time resolved measurements, and also provided data to compare with modeling results.

\subsection{Numerical developments}

A method has been developed to build a reliable numerical model of laser-induced shock into composite materials. This development has been presented through three main steps:

- Preliminary steps have enabled to correctly set the most important input parameter, namely the pressure profile resulting for the laser irradiation. Calibration has been detailed, and results fit with previous work.

- Parameter identification method has been established in three steps: 1. Identification of the influent parameters, 2. Identification of the elastic constants, 3. Adjustment of the damage thresholds. In the case of the tested composite, most influent parameters are Young's moduli for propagation below damage threshold, and interlaminar tensile strength for case for damage. Elastic constants have then been identified by matching calculation results to an experimental signal. This approach also led to the definition of the dynamic tensile strength. Averagely, a factor about 2 was necessary to get the dynamic parameters from the quasi-static ones.

- This set of parameters was then fully validated using experimental data from CFRP materials of various thicknesses, below and above the spallation threshold.

- Note that these parameters are only valid for the particular case of laser shock loading, and even more specific to nanosecond pulses. Using a completely different laser source, or shock source, would require to re-run the described identification procedure.

\subsection{Numerical results}

- On T800/M21 CFRP laminates first, the numerical modeling has confirmed the theoretical interpretation of the back face velocity signals. The interlaminar strength estimated through modeling $(275 \mathrm{MPa})$, is also quite close to the rough experimental value (240 MPa).

- Finally, bonded composites were investigated. Below the damage threshold, the numerical results have enabled to clearly understand the stress distribution within the material thickness during the wave propagation. Links with the corresponding back face velocity were drawn, to also explain these complex signals. Above the damage threshold, numerical results have shown that the maximum of stresses were located in the 
composite laminate, and not in the bondline. This observation clearly explains why failure was experimentally evidenced in the composite.

- Regarding the composite bonding adhesion test, this work has demonstrated that the used laser source was not really well adapted for testing such bonded assemblies. As an expert tool, this reliable model could be used to optimize the stress distribution and to steer an optimal shock configuration to perform an efficient shock wave adhesion test. One idea could be to tune the pulse duration to change the stresses distribution and thus better locate the first tensile stresses in the material. Investigations have been started and will be presented in another paper.

\section{Acknowledgments}

The research leading to these results has received funding from the European Union's Seventh Framework Program (FP7/20072013) under grant agreement $n^{\circ}$ ACP0-GA-2010-266226 (ENCOMB, Extended Non-Destructive Testing of Composite Bonds).

\section{References}

[1] Markus S, Tornow C, Dieckhoff S, Boustie M, Ecault R, Berthe L, et al. Extended non-destructive testing of composite bonds. In: Presented at the SAE international conference, Toulouse, France. Report No.: 2011-01-2514.

[2] Hoffmann M et al. ENCOMB: investigation of quality assurance concepts for adhesive bonding of aircraft composite structures by extended NDT. In: Proceedings of the 3rd international EASN workshop on aerostructures, 9-11 October, EASN Association, EASN-TIS and Politecnico di Milano.

[3] <www.encomb.eu>

[4] Markus S. Detection of contaminants on polymer surfaces using laser induced breakdown spectroscopy (LIBS). In: Mittal KL, editor. Polymer surface modification: relevance to adhesion, vol. 4. Utrecht: VSP.

[5] Albinsky K, Brune K, Dieckhoff S, Hesebeck O, Lommatzsch U, Markus S Advances in bonded repair of CFRP aircraft structures by surface inspection. In: Presented at the 2nd international conference on advanced composite materials and technologies for aerospace applications, Wrexham, United Kingdom. p. 11-3.

[6] Rock F, Barsan N, Weimar U. Electronic nose: current status and future trends. Chem Rev 2008;108:705-25.

[7] Di Palma P, De Vito S, Miglietta M, Massera E, Fattoruso G, Mastroianni B, et al CFRP surface contamination detection by an electronic nose device for quality assessment of adhesive bonds in lightweight aircraft structures. In: Presented at the 3rd international conference of engineering against failure (ICEAF III) 26th-28th June, Kos Island, Greece.

[8] Brune K, Dieckhoff S, Hoffmann M, Lima L, Stübing D, Tornow C. Pre-bond quality assurance of CFRP-surfaces by using optically stimulated electron emission. In: Presented at the Adhesion'13 conference, September 4th-6th, York, United Kingdom.

[9] Malinowski P, Wandowski T, Ostachowicz W. Characterization of CFRP using piezoelectric transducer and laser vibrometry. In: Presented at the 10th international conference on damage assessment of structures, July, 8th-10th, Dublin, Ireland.

[10] Malinowski P, Tserpes KI, Wandowski T, Skarbek L, Ostachowicz W. Composite bonds assessment using EMI technique. In: Presented at the 9th international workshop on structural health monitoring, September 10th-12th.

[11] Malinowski P, Wandowski T, Ostachowicz W. The use of electromechanical impedance conductance signatures for detection of weak adhesive bonds of carbon fibre-reinforced polymer. Struct Health Monit 2015;14(4):332-44.

[12] Ehrhart B. Quality assessment of CFRP bonded structures with active thermography techniques. In: Proceedings of the 5 th international symposium on NDT in aerospace, 13th-15th November, Singapore.

[13] Canal LP, Michaud V. Micro-scale modeling of water diffusion in adhesive composite joints. Compos Struct 2014;111:340-8. http://dx.doi.org/10.1016/ i.compstruct.2014.01.009.

[14] Canal LP, Sarfaraz R, Violakis G, Botsis J, Michaud V, Limberger HG. Monitoring strain gradients in adhesive composite joints by embedded fiber Bragg grating sensors. Compos Struct 2014;112:241-7. http://dx.doi.org/10.1016/ i.compstruct.2014.02.014.

[15] Sarfaraz R, Canal LP, Violakis G, Botsis J, Michaud V, Limberger HG. An experimental-numerical investigation of hydrothermal response in adhesively bonded composite structures. Compos Part A 2015;73:176-85. http://dx.doi. org/10.1016/j.compositesa.2015.03.005.

[16] Heichler G, Grundner T, Rau E. Ultrasonic frequency analysis. In: Presented at the 3rd international conference of engineering against failure (ICEAF III), 26th-28th June, Kos Island, Greece.
[17] Campagne B, Voillaume H. Development of laser ultrasonics: application to complex shape aeronautical parts. In: Presented at the 1 st international symposium on laser ultrasonics: science, technology and application, July 1618, Montreal, Canada. p. 16-8. <www.ndt.net>.

[18] Seyrkammer R, Galos R, Reitinger B, Kasberger J, Burgholzer P. NDT in composite bonding for aeronautic applications with laser ultrasound and infrared spectroscopy. In: Presented at the 3rd international conference of engineering against failure (ICEAF III), 26th28th June 2013, Kos Island, Greece.

[19] Croxford AJ, Potter J, Sapountzi K. Ultrasonic array inspection of weak bonds. In: Presented at the 3rd international conference of engineering against failure (ICEAF III), 26th-28th June, Kos Island, Greece.

[20] Yuan J, Gupta V. Measurement of interface strength by the modified laser spallation technique. J Appl Phys 1993;74(4):2388-410.

[21] Berthe L, Arrigoni M, Boustie M, Cuq-Lelandais JP, Broussillou C, Fabre G, et al. State-of-the-art laser adhesion test (LASAT). Nondestr Test Eval 2011. http:// dx.doi.org/10.1080/10589759.2011.573550.

[22] Bossi R et al. Laser bond testing. Mater Eval 2009;67:819-27.

[23] Perton M, Blouin A, Monchalin J-P. Adhesive bond testing of carbon-epoxy composites by laser shockwave. J Phys D Appl Phys 2010;44:034012.

[24] Ecault R, Boustie M, Touchard F, Pons F, Berthe L, Chocinski-Arnault L, et al. A study of composite material damage induced by laser shock waves. Compos Part A 2013;44:54-64. http://dx.doi.org/10.1016/i.compositesa.2013.05.015.

[25] Ecault R, Boustie M, Berthe L, Touchard F, Chocinski-Arnault L, Voillaume H, et al. Development of the laser shock wave adhesion test on bonded CFRP composite. Int J Struct Integrity 2014;5(4):253-61.

[26] Ehrhart B, Ecault R, Touchard F, Boustie M, Berthe L, Bockenheimer C, et al. Laser shock adhesion test for the control of weak adhesive bonded CFRP structures. Int J Adhes Adhes 2014;52:57-65.

[27] Illyas M, Espinosa C, Lachaud F, Salaün M. Simulation of dynamic delamination and mode I energy dissipation. In: Presented at the 7th international LS-DYNA users conference, Salzburg, Austria. <http://www.dynalook.com/>.

[28] Ilyas M, Lachaud F, Espinosa C, Michel L, Salaün M. Dynamic delamination modeling of unidirectional composites by cohesive finite elements. In: Presented at the 16th Journée Nationales sur les composites (JNC16), Toulouse, France, 10th-12th June.

[29] Heimbs S, Heller S, Middendorf P. Simulation of low velocity impact on composite plates with compressive preload. Bamberg: LS-DYNA Anwenderforum; 2008. <http://www.dynalook.com/>.

[30] LS-DYNA Keyword user's manual, vols. I and II. Version 971; May 2007.

[31] LS-DYNA Theory manual, compiled by John O. Hallquist; March 2006.

[32] Chang FK, Chang KY. A progressive damage model for laminated composites containing stress concentrations. J Compos Mater 1987;21:834-55.

[33] Thatte BS, Chandekar GS, Kelkar AD, Chaphalkar P. Studies on behavior of carbon and fiberglass epoxy composite laminates under low velocity impact loading using LS-DYNA, Presented at the 10th international LS-DYNA users' conference, Detroit, USA. <http://www.dynalook.com/>.

[34] Haynes R, Tan X, Armanios E. Effects of barely impact damage on bend-twist coupling. In: Presented at the 26th annual technical conference of ASC, September 26th-28th, Montreal, Quebec, Canada.

[35] Faggiani A, Falzon BG. Predicting low-velocity impact damage on a stiffened composite panel, published. Compos A 2010;41(2010):737-49.

[36] Lopes CS, Camanho PP, Gürdal Z, Maimí P, González EV. Low-velocity impact damage on dispersed stacking sequence laminates. Part II: numerical simulations. Compos Sci Technol 2009;69(2009):937-47.

[37] Anghileri M, Castelletti L-M, Milanese A, Semboloni A. Modeling hailstone impact onto composite material panel under a multi-axial state of stress. In: Presented at the 6th European LS-DYNA users' conference, Gothenburg, Sweden. <http://www.dynalook.com/>.

[38] Espinosa HD, Dwivedi S, Lu H-C. Modeling impact induced delamination of woven fiber reinforced composites with contact/cohesive laws. Comput Methods Appl Mech Eng 2000;183(2000):259-90.

[39] Yoshimura A, Nagakura K, Okabe T, Kusano H, Yamada M, Tanabe Y, Ogasawara T, Nakatani H, Ogihara S. 3D simulation of high-velocity impact damage progress in the CFRP laminates. In: Presented at the 15th European conference on composite materials (ECCM15), June 24th-28th, Venice, Italy.

[40] Allix O, Dommanget M, Gratton M, Héreil P-L. A multi-scale approach for the response of a $3 \mathrm{D}$ carbon/carbon composite under shock loading, published. Compos Sci Technol 2001;61:409-15.

[41] Yen C-F. Ballistic impact modeling of composite materials. In: Presented at the 7th international LS-DYNA users conference, Salzburg, Austria. <http:// www.dynalook.com/>.

[42] Deka LJ, Vaidya UK. LS-DYNA impact simulation of composite sandwich structures with balsa wood core. In: Presented at the 10th international LSDYNA users' conference, Detroit, USA. <http://www.dynalook.com/>.

[43] Lukyanov AA. An equation of state of a carbon-fibre epoxy composite under shock loading. Eur Phys J 2010;B 74:35-45. http://dx.doi.org/10.1140/epjb/ e2010-00043-4.

[44] Vignjevic R, Djordjevic N, De Vuyst T. Progressive damage in woven CFRP in presence of shock wave. In: Presented at the 15th European conference on composite materials (ECCM15), June 24th-28th, Venice, Italy.

[45] Wicklein M, Ryan S, White DM, Clegg RA. Hypervelocity impact on CFRP: testing, material modelling, and numerical simulation, published. Int J Impact Eng 2008;35:1861-9.

[46] Ryan S, Wicklein M, Mouritz A, Riedel W, Schäfer F, Thoma K. Theoretical prediction of dynamic composite material properties for hypervelocity impact simulations, published. Int J Impact Eng 2009;36(2009):899-912. 
[47] Fabbro R, Fournier J, Ballard P, Devaux D, Virmont J. Physical study of laser produced plasma in confined geometry. I Appl Phys 1990;68 (2):775-84.

[48] Berthe L, Fabbro R, Peyre P, Tollier L, Bartnicki E. Shock waves from a water confined laser-generated plasma. J Appl Phys 1997;82(6):2826-32.

[49] Antoun T, Seaman L, Curran DR, et al. Spall fracture. New-York: SpringerVerlag; 2002. ISBN 0-385-95500-3.

[50] Tollier L, Fabbro R, Bartnicki E. Study of laser-driven spallation process by VISAR interferometry technique. I. Laser-shock characterization. J Appl Phys 1998;83(3):1224.
[51] Cuq-Lelandais J-P. Etude du comportement dynamique de matériaux sous choc laser sub-picoseconde, [Thèse de l'ENSMA]. Ecole Nationale Supérieure de Mécanique et d'Aérotechnique, Ecole doctorale SIMMEA; 2010.

[52] Dandekar DP, Hall CA, Chhabildas LC, Reinhart WD. Shock response of a glassfiber-reinforced polymer composite, published. Compos Struct 2003;61:51-9.

[53] Ecault R, Berthe L, Touchard F, Boustie M, Lescoute E, Sollier A, et al Experimental and numerical investigations of shock and shear waves propagation induced by femtosecond laser irradiation in epoxy resins. J Phys D Appl Phys 2015;48:095501. http://dx.doi.org/10.1088/0022-3727/48/9/ $\underline{095501}$ 